\title{
Protective effect of Xin Mai Jia ultrafiltration extract on human umbilical vein endothelial cell injury induced by hydrogen peroxide and the effect on the NO-cGMP signaling pathway
}

\author{
YALING YIN $^{1 *}$, JIA WAN $^{2 *}$, PENG LI $^{3 *}$, YANLONG JIA $^{3}$, RUILI SUN ${ }^{4}$, \\ GUOPIN PAN $^{3}$ and GUANGRUI WAN ${ }^{5}$
}

${ }^{1}$ School of Basic Medical Sciences, Xinxiang Medical University, Xinxiang, Henan $453003 ;{ }^{2}$ Department of Nephrology,
The First Affiliated Hospital, Zhengzhou University, Zhengzhou, Henan $450052 ;{ }^{3}$ College of Pharmacy;
${ }^{4}$ Department of Inspection; ${ }^{5}$ Modern Technology Education Center, Xinxiang Medical University,
Xinxiang, Henan 453003, P.R. China

Received December 1, 2013; Accepted March 25, 2014

DOI: $10.3892 /$ etm.2014.1700

\begin{abstract}
The aim of the present study was to evaluate the protective effect of the ultrafiltration extract of Xin Mai Jia (XMJ) on a human umbilical vein endothelial cell (HUVEC) injury model induced by hydrogen peroxide $\left(\mathrm{H}_{2} \mathrm{O}_{2}\right)$, by providing experimental data to investigate the mechanism and efficacy underlying the therapeutic effects on atherosclerosis. HUVECs were first injured by $\mathrm{H}_{2} \mathrm{O}_{2}$ and then varying final concentrations of the Chinese herb extract were added. Effects of the XMJ extract on morphology, activity, monolayer permeability, biochemical indicators, cytokines, endothelial nitric oxide synthase (eNOS) protein content and eNOS gene expression in the HUVECs were analyzed. $\mathrm{H}_{2} \mathrm{O}_{2}$ significantly promoted HUVEC injury. The XMJ ultrafiltration extract significantly improved the morphological changes in the injured HUVECs. In addition, XMJ treatment increased cell activity and decreased monolayer permeability. The expression levels of intracellular adhesion molecule-1, vascular adhesion molecule-1, interleukin- 1 and -6 and nuclear factor- $\mathrm{\kappa} B$ decreased, while the expression levels of matrix metalloproteinase- 2 and tissue inhibitor of metalloproteinase- 2 increased with XMJ administration. Increased levels of nitric oxide (NO), eNOS protein and eNOS gene expression were also observed. Therefore, the XMJ ultrafiltration extract exhibits marked anti-inflammatory effects and antioxidant abilities. These properties significantly inhibited the $\mathrm{H}_{2} \mathrm{O}_{2}$-induced injury
\end{abstract}

Correspondence to: Professor Guangrui Wan, Modern Technology Education Center, Xinxiang Medical University, 45 Dongduan Wuyi Road, Xinxiang, Henan 453003, P.R. China

E-mail: guangruiw@126.com

*Contributed equally

Key words: Xin Mai Jia, human umbilical vein endothelial cell, hydrogen peroxide, atherosclerosis of HUVECs, which may be associated with the NO-cyclic guanosine monophosphate signaling pathway.

\section{Introduction}

Vascular endothelial cells, the natural barrier between the blood and tissue, secrete various vasoactive substances, cytokines and neurotransmitters, including nitric oxide (NO), interleukins (ILs), adhesion molecules, endothelin and tissue factors (1-3). These substances participate in and influence the organic movement of substances, blood coagulation, immune responses and other essential activities. Previous studies have shown that oxidative stress injury in vascular endothelial cells is the cause of various vascular diseases, including atherosclerosis (AS), diabetes and hypertension (4,5). Oxidative stress generates reactive oxygen species (ROS), such as the superoxide anion $\left({ }^{\circ} \mathrm{O}^{2-}\right)$, the hydroxyl radical $\left({ }^{\circ} \mathrm{OH}\right)$ and hydrogen peroxide $\left(\mathrm{H}_{2} \mathrm{O}_{2}\right)$. ROS bind to the nuclear receptor of vascular endothelial and smooth muscle cells as a ligand, or directly regulate gene expression as signaling molecules. These functions enhance the adhesion and migration of monocytes to the tunica intima, which is important during the development of AS $(6,7)$.

NO is a neurotransmitter secreted by vascular endothelial cells, which can inhibit monocyte-macrophage and platelet adhesion, decrease the monolayer permeability of vascular endothelial cells and reduce vascular endothelial cell and smooth muscle cell proliferation $(8,9)$. Previous studies have shown that $30 \%$ of NO in the blood is derived from endothelial nitric oxide synthase (eNOS) genes expressed by vascular endothelial cells. NO diffuses to nearby endothelial and smooth muscle cells, activates soluble guanosine monophosphate cyclase within the cytoplasm, decomposes guanosine triphosphate and generates cyclic guanosine monophosphate (cGMP), which results in biological effects, including vasodilation, that play an important role in AS (10).

Xin Mai Jia (XMJ) is a traditional Chinese medicine (TCM) used in the treatment of AS that can effectively inhibit AS occurrence and development (11). XMJ is prepared using 
the following raw materials based on weight: Functional red kojic rice powder, 10-35\%; kudzu flavonoid powder, 1-10\%; soybean isoflavone powder, 1-8\%; bamboo leaf flavone powder, 1-8\%; resveratrol powder, 1-8\%; hawthorn powder, 1-6\%; Gastrodia powder, 1-6\%; Auricularia auricula powder, $1-30 \%$; hippocampus powder, $0.1-0.2 \%$; astaxanthin powder, 0.008-0.04\%; menthol powder, 0.1-0.3\%; and resistant starch, $20-50 \%$. To investigate the inhibitory mechanism of XMJ on the occurrence and development of AS, the present study evaluated the effects of intervention with the ultrafiltration extract from XMJ on a human umbilical vein endothelial cell (HUVEC) injury model induced by $\mathrm{H}_{2} \mathrm{O}_{2}$. The effect on the NO-cGMP signaling pathway, caused by the inhibition of the $\mathrm{H}_{2} \mathrm{O}_{2}$-induced injury, was also investigated.

\section{Materials and methods}

Drugs and chemicals. XMJ crude drugs were purchased from Beijing Tong Ren Tang Co., Ltd. (Beijing, China). Phospho-eNOS-3 antibodies were purchased from Beijing Boaosen Biotechnology Co., Ltd. (BS-3447R; Beijing, China), horseradish peroxidase-labeled goat anti-rabbit IgG (heavy and light chains) antibody was purchased from Beijing Zhongshan Golden Bridge Biotechnology Co., Ltd. (PV-9003; Beijing, China) and Cy3-labeled goat anti-rabbit IgG (heavy and light chain) antibodies were purchased from Biyuntian Institute of Biotechnology (P0183; China). Lovastatin, $\mathrm{H}_{2} \mathrm{O}_{2}$, diethyl carbonate, XTT, phenazine methosulfate (PMS), diethylpyrocarbonate and avian myeloblastosis virus were purchased from Sigma-Aldrich (St. Louis, MO, USA). Zhibituo was purchased from Chengdu Diao Jiuhong Pharmaceutical Factory (Chengdu, China). Hematoxylin and eosin (HE) and Coomassie Brilliant Blue stains were purchased from Changsha Lixin Biotechnology Co., Ltd. (Changsha, China). Kits for the detection of malondialdehyde (MDA), superoxide dismutase (SOD), NO, interleukin (IL)-1, IL-6, intracellular adhesion molecule (ICAM)-1, vascular adhesion molecule (VCAM)-1, matrix metalloproteinase (MMP)-2, tissue inhibitor of metalloproteinase (TIMP)-2 and nuclear factor (NF)- $\kappa \mathrm{B}$ were purchased from R\&D Systems (Minneapolis, MN, USA). Other reagents were analytically pure and made in China.

Cell experiment protocol. HUVECs were obtained from HUVEC cell lines purchased from Acti Corp. (Irvine, CA, USA) and were routinely maintained in phenol-red containing Dulbecco's modified Eagle's medium (Gibco Construction, LLC, Cleveland, TN, USA), which was supplemented with $15 \%$ newborn calf serum, $100 \mathrm{U} / \mathrm{ml}$ penicillin and $0.1 \mathrm{mg} / \mathrm{ml}$ phytomycin, in a $37^{\circ} \mathrm{C}$ incubator in an atmosphere of $5 \% \mathrm{CO}_{2}$. The third generation of HUVECs were used in the study. The cells were randomly divided into eight groups and incubated for $24 \mathrm{~h}$ with the corresponding drugs. The first group of cells were incubated in Kreb's solution and were classified as the blank control group $(n=6)$. The second group of cells were incubated in $500 \mathrm{mg} / \mathrm{l} \mathrm{XMJ}$ and were classified as the XMJ control group $(n=6)$. The third group of cells were incubated in $200 \mu \mathrm{mol} / 1 \mathrm{H}_{2} \mathrm{O}_{2}$ and were classified as the model group $(\mathrm{n}=6)$. The fourth group of cells were incubated in $1 \mu \mathrm{mol} / 1$ lovastatin and $200 \mu \mathrm{mol} / 1 \mathrm{H}_{2} \mathrm{O}_{2}$ and were classified as the lovastatin group $(n=6)$. The fifth group of cells were incubated in $50 \mu \mathrm{mol} / 1$ zhibituo and $200 \mu \mathrm{mol} / 1 \mathrm{H}_{2} \mathrm{O}_{2}$ and were classified as the zhibituo group $(\mathrm{n}=6)$. The sixth group of cells were incubated in $25 \mu \mathrm{mol} / 1 \mathrm{XMJ}$ and $200 \mu \mathrm{mol} / 1 \mathrm{H}_{2} \mathrm{O}_{2}$ and were classified as the low-dose XMJ group $(n=6)$. The seventh group of cells were incubated in $50 \mu \mathrm{mol} / 1 \mathrm{XMJ}$ and $200 \mu \mathrm{mol} / 1 \mathrm{H}_{2} \mathrm{O}_{2}$ and were classified as the middle-dose XMJ group $(n=6)$. Finally, the eighth group of cells were incubated in $50 \mu \mathrm{mol} / 1 \mathrm{XMJ}$ and $200 \mu \mathrm{mol} / 1 \mathrm{H}_{2} \mathrm{O}_{2}$ and were classified as the high-dose XMJ group $(n=6)$. Following the individual treatments, the cultured cells were obtained for the subsequent tests.

Ultrafiltration membrane extract preparation for XMJ. In total, 1,000 g XMJ crude drugs were placed in a container filled with $6,000 \mathrm{ml}$ water, which was heated in a microwave oven for $1 \mathrm{~h}$ at $1,000 \mathrm{~W}$. A four-gauze filter was used to obtain one type of liquid medicine. Next, 6,000 $\mathrm{ml}$ water was added to the container again prior to repeating the aforementioned procedure. Following the production of two types of liquid medicine, the liquid was filtered with sterile absorbent cotton. Ultrafiltration technology of refining XMJ was then used for water decoction under $0.5 \mathrm{kPa} / \mathrm{m}^{3}$ at $25^{\circ} \mathrm{C}$ and $100 \mathrm{l} / \mathrm{h} / \mathrm{m}^{2}$. The $5,000 \mathrm{ml}$ filtrate was condensed to $1,000 \mathrm{ml}$, which was equivalent to $1 \mathrm{ml}$ liquid medicine containing $1 \mathrm{~g}$ XMJ. Finally, the mother liquor was labeled and stored in a refrigerator at $4^{\circ} \mathrm{C}$ prior to use.

HUVEC staining. Cell growth on the wall of the bottle was observed in each experimental group. The supernatant in the 96-well plate was discarded and the cells were washed three times with phosphate-buffered saline (PBS; $\mathrm{pH}$ 7.4) for $1 \mathrm{~min}$ for each repetition. Next, the cells were soaked in $95 \%$ ethanol for $20 \mathrm{~min}$ and washed with PBS twice at $1 \mathrm{~min}$ for each repetition. Hematoxylin was used to dye the cells for 2-3 min and then the cells were washed with pure water. The cells were observed under a microscope (Olympus Corp., Tokyo, Japan). For deeply-stained nuclei, a $1 \%$ solution of hydrochloric acid and alcohol was used to dilute the cells into dichroic for $5 \mathrm{sec}$. The cells were washed with pure water and placed in $70 \%$ alcohol for dehydration for $10 \mathrm{~min}$ and then in $90 \%$ alcohol for $10 \mathrm{~min}$. The cells were washed with distilled water and dyed using alcoholic eosin for 2-3 min. Finally, the cells were dried and mounted on slides using neutral gum.

HUVEC activity detection. When the concentration of the cells growing on the walls of the bottles in each experimental group reached $10^{6} \mathrm{cells} / \mathrm{cm}^{2}$, the following steps were undertaken. The cells were washed twice with PBS, $0.25 \%$ trypsin was added and the flasks were shaken to remove the cells from the wall of the bottle with the aid of nozzle-pipe blowing. Thiophene azole blue solution $\left(1 \mathrm{~g} / 1 ; 37^{\circ} \mathrm{C}\right.$; volume fraction, $\left.5 \%\right)$ was added to each well and $10-\mu 1$ samples were obtained from each well and added to an automatic cell counting board (Countstar). The viability rate, average compactness and aggregation rate of the cells in each group were measured using a Countstar automatic cell-counting instrument.

HUVEC monolayer permeability determination. According previous studies $(12,13)$, the osmotic reflection coefficient $(\sigma)$ and the endothelial monolayer filtration coefficient (Kf; $\mu \mathrm{l} / \mathrm{min} / \mathrm{cm}^{2} / \mathrm{kPa}$ ) were calculated according to the following 
formulas: $\mathrm{Kf}=$ total water flux $(\mathrm{Jv}) /(\Delta \mathrm{P}-\sigma \cdot \Delta \pi) ; \sigma=1-\mathrm{C}_{\mathrm{F}} / \mathrm{C}_{\mathrm{P}}$; $\pi(\mathrm{kPa})=\mathrm{C}(\mathrm{mOsm} / \mathrm{l}) \times 2.6(\mathrm{kPa} / \mathrm{l} / \mathrm{mOsm})$; where $\mathrm{Jv}(\mu l \cdot \mathrm{min}$ $\left.{ }^{1} \cdot \mathrm{cm}^{-2}\right)=\mathrm{V} / \mathrm{S} \cdot \mathrm{min} ; \mathrm{C}_{\mathrm{P}}$ was the upper chamber white protein concentration; $\mathrm{C}_{\mathrm{F}}$ was the inferior vena albumin concentration; $\mathrm{C}$ was the albumin milli seepage quantity concentration; $\Delta \mathrm{P}$ was the perfusion pressure; and $\pi$ was the colloid osmotic pressure.

HUVEC supernatant fluid biochemical indicator detection. Cells were seeded into six-well plates at $2 \mathrm{ml}$ per well in order for the samples to be treated as a group, according to the aforementioned method. Cell supernatant fluid biochemical indicators were detected. Culture fluids were obtained separately to determine the SOD, MDA and NO concentration, as described in the kits.

ELISA. Cells were seeded into six-well plates at $2 \mathrm{ml}$ per well in order for the samples to be treated as a group, according to the aforementioned method. Following the instructions on the ELISA kit, cell supernatant fluids were obtained from the wells and the optical density (OD) value of each well was measured at a wavelength of $450 \mathrm{~nm}$. The acquired absorbance value of the OD was regarded as the ordinate and the concentration of the standard liquid was considered as the abscissa. A curve was constructed, from which the curve equation was calculated. By substituting the OD values of the samples into the equation of the standard curve, IL-1, IL-6, ICAM-1, VCAM-1, MMP-2, TIMP-2 and NF-кB levels were calculated.

Western blot analysis. As previously described (14), the supernatant in the 96-well plates was discarded and the eNOS protein content of each experimental group of adhered HUVECs was assayed. Pre-cooled cell lysates were added, proteins were obtained and the protein concentration was detected using the bicinchoninic acid method.

Immunohistochemical method. Cells were soaked in $95 \%$ ethanol for $20 \mathrm{~min}$, washed with PBS twice for 1 min per wash and sealed with animal serum. An appropriate dilution (1:400) of phospho-eNOS-3-endothelial antibodies was added and the cells were incubated overnight at $4^{\circ} \mathrm{C}$. Next, horseradish peroxidase-labeled goat anti-rabbit IgG antibodies were added. Mayer's hematoxylin was used to stain the cells for a second time, and the cells were dehydrated and dried using gradient alcohol. Transparent xylene was also added and the cells were mounted on slides using neutral gum. Finally, the cells were observed under a microscope and images were obtained. The results were processed and analyzed using analysis software for OD.

Immunofluorescence. The supernatant in the 96-well plates was discarded and $0.01 \mathrm{~mol} / 1 \mathrm{PBS}$ ( $\mathrm{pH}$ 7.4) was added dropwise into the specimen sheet to be tested, which was discarded after $10 \mathrm{~min}$. To keep the specimen wet to a certain extent, a 1:200 phospo-eNOS-3-endothelial antibody dilution was added and the cells were incubated overnight at $4^{\circ} \mathrm{C}$. The membranes were washed with Tris-buffered saline Tween-20 three times and a dilution $(1: 1,000)$ of $\mathrm{Cy} 3$-labeled goat anti-rabbit $\mathrm{IgG}$ antibodies were added and used to completely cover the specimens. The specimens were placed into an enamel box with a lid and incubated for $30 \mathrm{~min}$. The slides were removed from the enamel box and placed on the slide shelves. Next, the slides were washed with $0.01 \mathrm{~mol} / \mathrm{l} \mathrm{PBS}(\mathrm{pH}$ 7.4) and soaked in three water jars containing $0.01 \mathrm{~mol} / \mathrm{l} \mathrm{PBS}$ ( $\mathrm{pH}$ 7.4). The specimens were processed and analyzed using analysis software for OD.

Quantitative polymerase chain reaction ( $q P C R)$. Total cellular RNA was extracted using a TRIzol reagent kit. The primers were synthesized by Takara Biotechnology Dalian Co., Ltd. (Dalian, China) and the forward and reverse primer sequences (5'-3') were as follows: e1, GGGACCACATAGGTGTCTGC; and e2, CCAGCACAGCTACAGTGAGG. The $10-\mu 1$ reaction system was composed of $5 \mu \mathrm{l}$ SYBR Premix Taq TM (2X) reaction liquid, $0.25 \mu \mathrm{l}$ PCR forward primer $(10 \mu \mathrm{M}), 0.25 \mu \mathrm{l}$ PCR reverse primer $(10 \mu \mathrm{M}), 0.5 \mu \mathrm{l} \mathrm{cDNA}$ template and $4 \mu \mathrm{l}$ deionized water. The recorded temperatures of the melting curve ranged between 60 and $95^{\circ} \mathrm{C}$. Following the reaction, the PCR samples were processed separately by agarose gel electrophoresis to verify whether the fragments had been amplified. When the qPCR reaction had been completed, the data were collected and analyzed using the computer analysis software, PikoReal Software 2.1 (Thermo Fisher Scientific, Waltham, MA, USA). The corresponding Ct value was calculated after adjusting the baseline cycle threshold according to the requirements of the software.

Statistical analysis. All data are expressed as the mean \pm standard error. One-way analysis of variance and the Student-Newman-Keuls test for multiple comparisons were used to compare the data among the various groups. Statistical analysis was performed using the SPSS 13.0 statistical software (SPSS, Inc., Chicago, IL, USA) and $\mathrm{P}<0.05$ was considered to indicate a statistically significant difference.

\section{Results}

Protective effect of XMJ on HUVEC injury induced by $\mathrm{H}_{2} \mathrm{O}_{2}$ observed under a microscope. HUVECs stained with HE were observed under a microscope (magnification, $x 400$ ) and the observations were as follows. HUVEC apoptosis was significantly reduced in the high-dose XMJ group. Cytoplasmic staining was relatively uniform and the metachromatic particles of the nuclei were not marked. The cells were arranged closely and their morphology was normal. Evident differences were identified when comparing these cells with the model group. Higher-dose XMJ demonstrated a significant protective effect on the HUVEC injury induced by $\mathrm{H}_{2} \mathrm{O}_{2}$. Lovastatin and zhibituo also exhibited marked protective effects, however, their protective effects with regard to morphology were relatively weaker when compared with the high-dose XMJ group. The protective effects of the low- and middle-dose XMJ groups were significantly weaker than that of the high-dose XMJ group, indicating the dependence of the protective effect on XMJ dosage (Fig. 1).

Effect of XMJ on HUVEC activity. In the high-dose XMJ group, the rate of HUVEC activity was $89.54 \%$, the average degree of compaction was 0.77 and the speed rate of polymerization was $60.83 \%$. In the model group, the activity rate of the HUVECs was $54.13 \%$, the average degree of compaction 
Table I. Protective effects of XMJ on the $\mathrm{H}_{2} \mathrm{O}_{2}$-induced decrease in the permeability of the HUVEC monolayer ( $n=6$; mean \pm SE).

\begin{tabular}{|c|c|c|c|}
\hline Group & $\mathrm{Jv}\left(\mu \mathrm{l} / \mathrm{min} / \mathrm{cm}^{2}\right)$ & $\mathrm{Kf}\left(\mu 1 / \mathrm{min} / \mathrm{cm}^{2} / \mathrm{Kpa}\right)$ & $\sigma$ \\
\hline Blank control & $27.26 \pm 4.63^{\mathrm{a}, \mathrm{b}}$ & $11.34 \pm 2.87^{\mathrm{a}, \mathrm{b}}$ & $0.54 \pm 0.07^{\mathrm{a}, \mathrm{b}}$ \\
\hline XMJ control & $28.43 \pm 5.35^{\mathrm{a}, \mathrm{b}}$ & $11.54 \pm 2.89^{\mathrm{a}, \mathrm{b}}$ & $0.55 \pm 0.07^{\mathrm{a}, \mathrm{b}}$ \\
\hline Model & $44.47 \pm 8.56^{\mathrm{b}, \mathrm{c}}$ & $17.66 \pm 3.43^{\mathrm{b}, \mathrm{c}}$ & $0.29 \pm 0.03^{b, c}$ \\
\hline Lovastatin & $33.45 \pm 6.49^{\mathrm{a}, \mathrm{b}, \mathrm{c}}$ & $14.46 \pm 2.98^{\mathrm{a}, \mathrm{b}, \mathrm{c}}$ & $0.38 \pm 0.07^{\mathrm{a}, \mathrm{b}, \mathrm{c}}$ \\
\hline Zhibituo & $35.32 \pm 5.12^{\mathrm{a}, \mathrm{b}, \mathrm{c}}$ & $14.64 \pm 2.39^{\mathrm{a}, \mathrm{b}, \mathrm{c}}$ & $0.43 \pm 0.06^{\mathrm{a}, \mathrm{b}, \mathrm{c}}$ \\
\hline Low-dose XMJ & $34.34 \pm 5.43^{\mathrm{a}, \mathrm{b}, \mathrm{c}}$ & $14.54 \pm 2.32^{\mathrm{a}, \mathrm{b}, \mathrm{c}}$ & $0.41 \pm 0.08^{\mathrm{a}, \mathrm{b}, \mathrm{c}}$ \\
\hline Medium-dose XMJ & $30.12 \pm 5.67^{\mathrm{a}, \mathrm{b}, \mathrm{c}}$ & $12.28 \pm 2.13^{\mathrm{a}, \mathrm{b}, \mathrm{c}}$ & $0.46 \pm 0.08^{\mathrm{a}, \mathrm{b}, \mathrm{c}}$ \\
\hline High-dose XMJ & $29.43 \pm 7.53^{\mathrm{a}, \mathrm{c}}$ & $12.43 \pm 2.24^{\mathrm{a}, \mathrm{c}}$ & $0.59 \pm 0.08^{\mathrm{a}, \mathrm{c}}$ \\
\hline
\end{tabular}

${ }^{\mathrm{a}} \mathrm{P}<0.05$, vs. model group; ${ }^{\mathrm{b}} \mathrm{P}<0.05$, vs. high-dose XMJ group; ${ }^{\mathrm{c}} \mathrm{P}<0.05$, vs. blank control group. XMJ, Xin Mai Jia; HUVEC, human umbilical vein endothelial cell; SE, standard error; Kf, endothelial monolayer filtration coefficient; $\sigma$, osmotic reflection coefficient; Jv, total water flux; $\mathrm{H}_{2} \mathrm{O}_{2}$, hydrogen peroxide.
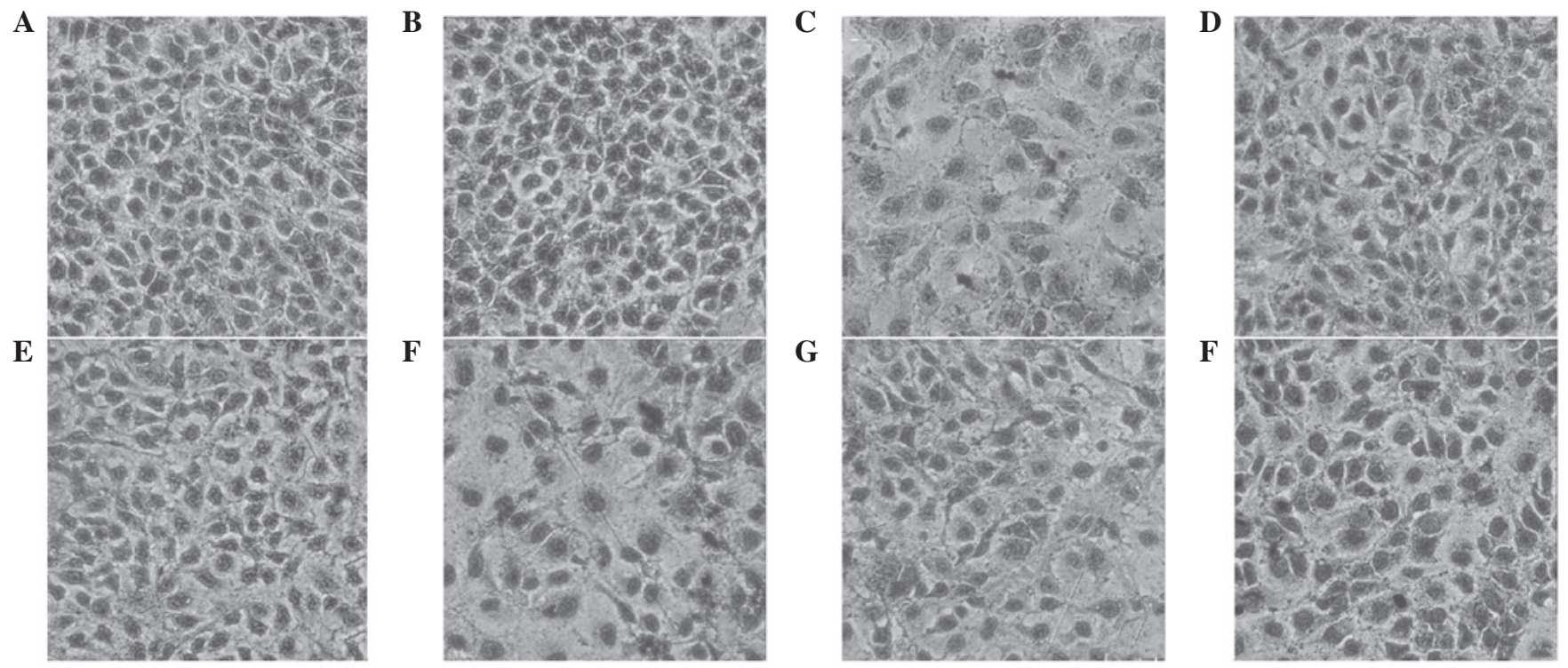

Figure 1. Microscopic images showing the protective effect of XMJ on HUVEC injury induced by $\mathrm{H}_{2} \mathrm{O}_{2}$ (magnification, $\mathrm{x} 400$; HE stain) in the (A) blank control, (B) XMJ control, (C) model, (D) lovastatin, (E) zhibituo, (F) low-dose XMJ, (G) medium-dose XMJ and (H) high-dose XMJ groups. XMJ, Xin Mai Jia; HUVEC, human umbilical vein endothelial cell; HE, hematoxylin and eosin; $\mathrm{H}_{2} \mathrm{O}_{2}$, hydrogen peroxide.

was 0.78 and the speed rate of polymerization was $52.52 \%$. These results exhibited statistically significant differences $(\mathrm{P}<0.05)$. The significant increase in the HUVEC activity rate in the high-dose XMJ group demonstrated that a high dosage of XMJ exhibits a significant protective effect on the reduction in the activity rate of injured HUVECs induced by $\mathrm{H}_{2} \mathrm{O}_{2}$. Lovastatin and zhibituo also demonstrated marked protective effects on the $\mathrm{H}_{2} \mathrm{O}_{2}$-induced reduction in the activity rate of the HUVECs, and when compared with the model group, a significant difference $(\mathrm{P}<0.05)$ was observed. However, when compared with the high-dose XMJ group, the differences in the activity rate of the HUVECs in the lovastatin and zhibituo groups were not statistically significant. The protective effects of the low- and middle-dose XMJ groups on the activity rate of the HUVECs induced by $\mathrm{H}_{2} \mathrm{O}_{2}$ were significantly weaker than that of the high-dose XMJ group, confirming that the effect was dependent on XMJ dosage. However, the differences in the average degree of compaction and the speed rate of polymerization in the low-, middle- and high-dose XMJ groups were not statistically significant ( $\mathrm{P}>0.05$; Fig. 2).

Protective effect of XMJ on the reduction of monolayer permeability in HUVEC injury induced by $\mathrm{H}_{2} \mathrm{O}_{2}$. In the high-dose XMJ group, the Jv of the HUVECs was $29.43 \pm 7.53 \mu 1 / \mathrm{min} / \mathrm{cm}^{2}$, the $\mathrm{Kf}$ was $12.43 \pm 2.24 \mu \mathrm{l} / \mathrm{min} / \mathrm{cm}^{2} / \mathrm{kPa}$ and the $\sigma$ was $0.59 \pm 0.08$. In the model group, the Jv of the HUVECs was $44.47 \pm 8.56 \mu 1 / \mathrm{min} / \mathrm{cm}^{2}$, the Kf was $17.66 \pm 3.43 \mu \mathrm{l} / \mathrm{min} / \mathrm{cm}^{2} / \mathrm{kPa}$ and the $\sigma$ was $0.29 \pm 0.03$. Compared with the model group, the Jv of the HUVECs in the high-dose XMJ group significantly decreased. Statistically significant differences $(\mathrm{P}<0.05)$ were also identified in the $\mathrm{Kf}$, which markedly decreased in the high-dose XMJ group, as well as the $\sigma$, which significantly increased. These results indicated that high-dose XMJ demonstrated marked protective effects on the reduction in HUVEC monolayer permeability 

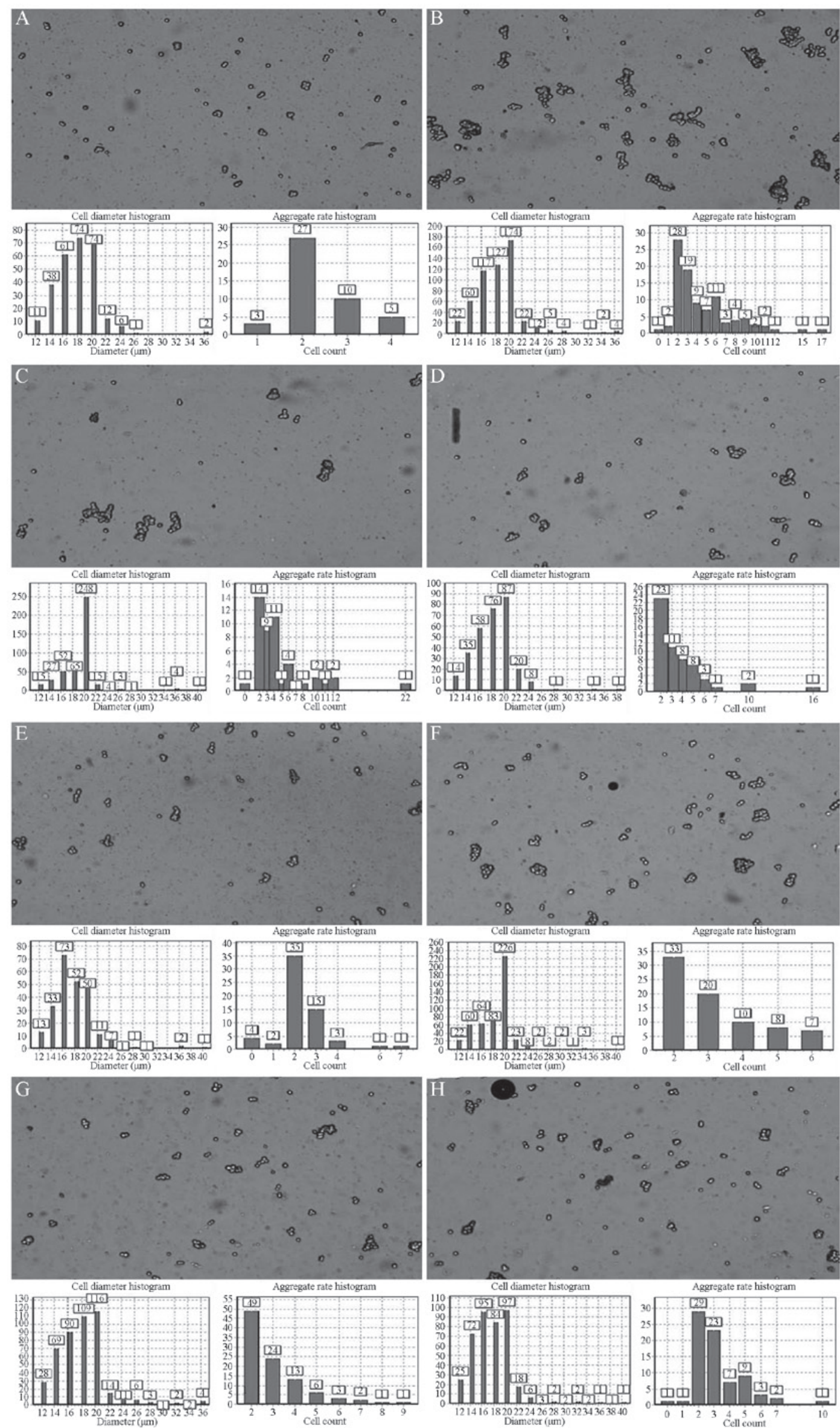

Figure 2. Effect of XMJ on the activity levels of HUVECs in the (A) blank control, (B) XMJ control, (C) model, (D) lovastatin, (E) zhibituo, (F) low-dose XMJ, (G) medium-dose XMJ and (H) high-dose XMJ groups, as determined by a Countstar automatic cell counter. XMJ, Xin Mai Jia; HUVECs, human umbilical vein endothelial cells; $\mathrm{H}_{2} \mathrm{O}_{2}$, hydrogen peroxide. 
Table II. Effect of XMJ on the levels of supernatant cytokines in HUVECs induced by $\mathrm{H}_{2} \mathrm{O}_{2}(\mathrm{n}=6$; mean $\pm \mathrm{SE})$.

\begin{tabular}{|c|c|c|c|c|c|c|}
\hline Group & $\begin{array}{c}\text { ICAM-1 } \\
(\mathrm{ng} / \mathrm{l})\end{array}$ & $\begin{array}{l}\text { VCAM-1 } \\
(\mu \mathrm{g} / 1)\end{array}$ & $\begin{array}{l}\text { IL-1 } \\
(\mathrm{ng} / \mathrm{l})\end{array}$ & $\begin{array}{l}\text { IL-6 } \\
\text { (ng/l) }\end{array}$ & $\begin{array}{c}\text { MMP-2 } \\
(\mu \mathrm{g} / 1)\end{array}$ & $\begin{array}{c}\text { TIMP-2 } \\
(\mathrm{pg} / \mathrm{l})\end{array}$ \\
\hline Blank control & $28.91 \pm 3.65^{\mathrm{a}, \mathrm{b}}$ & $36.49 \pm 1.22^{\mathrm{a}, \mathrm{b}}$ & $14.23 \pm 1.25^{\mathrm{a}, \mathrm{b}}$ & $5.93 \pm 0.45^{\mathrm{a}, \mathrm{b}}$ & $0.622 \pm 0.09^{\mathrm{a}, \mathrm{b}}$ & $1925.88 \pm 236.12^{\mathrm{a}, \mathrm{b}}$ \\
\hline XMJ control & $36.33 \pm 4.39^{a, b}$ & $38.78 \pm 2.39^{\mathrm{a}, \mathrm{b}}$ & $13.93 \pm 1.36^{\mathrm{a}, \mathrm{b}}$ & $6.51 \pm 0.65^{\mathrm{a}, \mathrm{b}}$ & $0.647 \pm 0.07^{\mathrm{a}, \mathrm{b}}$ & $2084.74 \pm 268.99^{\mathrm{a}, \mathrm{b}}$ \\
\hline Model & $71.18 \pm 6.67^{\mathrm{b}, \mathrm{c}}$ & $44.81 \pm 2.09^{\mathrm{b}, \mathrm{c}}$ & $18.34 \pm 2.14^{\mathrm{b}, \mathrm{c}}$ & $7.24 \pm 0.92^{\mathrm{b}, \mathrm{c}}$ & $0.608 \pm 0.07^{b, c}$ & $1739.31 \pm 254.39^{\mathrm{b}, \mathrm{c}}$ \\
\hline Lovastatin & $38.55 \pm 4.16^{\mathrm{a}, \mathrm{c}}$ & $35.84 \pm 1.96^{\mathrm{a}, \mathrm{c}}$ & $14.63 \pm 1.57^{\mathrm{a}, \mathrm{c}}$ & $6.05 \pm 0.78^{\mathrm{a}, \mathrm{c}}$ & $0.683 \pm 0.08^{\mathrm{a}, \mathrm{c}}$ & $1742.06 \pm 156.36^{\mathrm{a}, \mathrm{c}}$ \\
\hline Zhibituo & $34.10 \pm 4.12^{\mathrm{a}, \mathrm{c}}$ & $36.49 \pm 2.68^{\mathrm{a}, \mathrm{c}}$ & $14.79 \pm 1.69^{\mathrm{a}, \mathrm{c}}$ & $6.19 \pm 0.65^{\mathrm{a}, \mathrm{c}}$ & $0.622 \pm 0.07^{\mathrm{a}, \mathrm{c}}$ & $1475.53 \pm 124.82^{\mathrm{a}, \mathrm{c}}$ \\
\hline Low-dose XMJ & $62.78 \pm 5.47^{\mathrm{a}, \mathrm{b}, \mathrm{c}}$ & $38.94 \pm 2.47^{\mathrm{a}, \mathrm{b}, \mathrm{c}}$ & $15.49 \pm 2.31^{\mathrm{a}, \mathrm{b}, \mathrm{c}}$ & $6.48 \pm 0.77^{\mathrm{a}, \mathrm{b}, \mathrm{c}}$ & $0.612 \pm 0.06^{\mathrm{a}, \mathrm{b}, \mathrm{c}}$ & $2137.27 \pm 213.29^{\mathrm{a}, \mathrm{b}, \mathrm{c}}$ \\
\hline Medium-dose XMJ & $36.33 \pm 7.32^{\mathrm{a}, \mathrm{c}}$ & $36.66 \pm 1.58^{\mathrm{a}, \mathrm{c}}$ & $14.75 \pm 2.04^{\mathrm{a}, \mathrm{c}}$ & $6.05 \pm 0.84^{\mathrm{a}, \mathrm{c}}$ & $0.671 \pm 0.07^{\mathrm{a}, \mathrm{c}}$ & $2605.99 \pm 222.17^{\mathrm{a}, \mathrm{c}}$ \\
\hline High-dose XMJ & $39.29 \pm 4.57^{\mathrm{a}, \mathrm{b}, \mathrm{c}}$ & $43.38 \pm 2.39^{\mathrm{a}, \mathrm{b}, \mathrm{c}}$ & $16.07 \pm 2.55^{\mathrm{a}, \mathrm{b}, \mathrm{c}}$ & $7.21 \pm 0.98^{\mathrm{a}, \mathrm{b}, \mathrm{c}}$ & $0.643 \pm 0.07^{\mathrm{a}, \mathrm{b}, \mathrm{c}}$ & $1579.37 \pm 123.47^{\mathrm{a}, \mathrm{b}, \mathrm{c}}$ \\
\hline
\end{tabular}

${ }^{\mathrm{a}} \mathrm{P}<0.05$, vs. model group; ${ }^{\mathrm{b}} \mathrm{P}<0.05$, vs. medium-dose XMJ group; ${ }^{\mathrm{C}} \mathrm{P}<0.05$, vs. blank control group. XMJ, Xin Mai Jia; HUVECs, human umbilical vein endothelial cells; SE, standard error; ICAM, intercellular adhesion molecule; VCAM, vascular cell adhesion molecule; IL, interleukin, MMP, matrix metalloproteinase; TIMP, tissue inhibitor of metalloproteinase; $\mathrm{H}_{2} \mathrm{O}_{2}$, hydrogen peroxide.

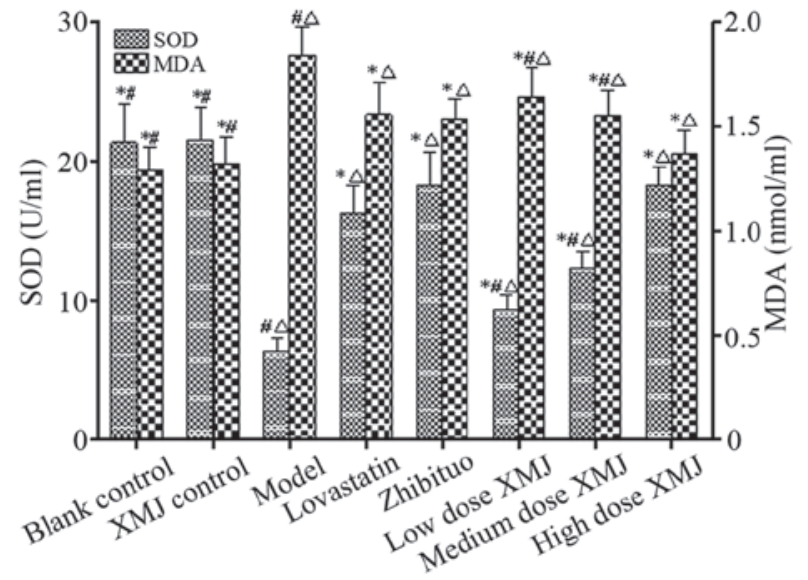

Figure 3. Effect of XMJ on the concentration of SOD and MDA in the supernatants of HUVECs induced by $\mathrm{H}_{2} \mathrm{O}_{2}$. "P $\mathrm{P} 00.05$, vs. model group; ${ }^{\text {}} \mathrm{P}<0.05$, vs. high-dose XMJ group; ${ }^{\wedge} \mathrm{P}<0.05$, vs. blank control group. XMJ, Xin Mai Jia; HUVECs, human umbilical vein endothelial cells; SOD, superoxide dismutase; MDA, maldionaldehyde; $\mathrm{H}_{2} \mathrm{O}_{2}$, hydrogen peroxide.

induced by $\mathrm{H}_{2} \mathrm{O}_{2}$. Lovastatin and zhibituo also exhibited evident protective effects and statistically significant differences $(\mathrm{P}<0.05)$ were observed when compared with the model group. However, the protective effects of high-dose XMJ were more significant than those of lovastatin and zhibituo $(\mathrm{P}<0.05)$. The protective effects of low- and middle-dose $\mathrm{XMJ}$, based on the by $\mathrm{H}_{2} \mathrm{O}_{2}$-induced decrease in the permeability of the HUVEC monolayer, were significantly weaker than that of high-dose XMJ $(\mathrm{P}<0.05)$, thus, the protective effects were dependent on the dose of XMJ (Table I).

Effect of XMJ on the concentration of SOD and MDA in the supernatant of $\mathrm{HUVECs}$ induced by $\mathrm{H}_{2} \mathrm{O}_{2}$. In the high-dose XMJ group, the concentrations of SOD and MDA were $18.21 \pm 1.39 \mathrm{U} / \mathrm{ml}$ and $1.37 \pm 0.26 \mathrm{nmol} / \mathrm{ml}$, respectively. In the model group, the concentration of SOD was $6.35 \pm 0.87 \mathrm{U} / \mathrm{ml}$ and the concentration of MDA was $1.84 \pm 0.26 \mathrm{nmol} / \mathrm{ml}$. Compared with the model group, statistically significant differences $(\mathrm{P}<0.05)$ were observed in the high-dose XMJ group with regard to SOD concentration, which significantly increased, and MDA, which significantly decreased. Lovastatin and zhibituo also exhibited marked suppressive effects on the decrease of supernatant SOD levels and the increase of supernatant MDA levels in the HUVEC injury model induced by $\mathrm{H}_{2} \mathrm{O}_{2}$. The results were statistically significant $(\mathrm{P}<0.05)$ when compared with the model group, however, when compared with the high-dose XMJ group, the differences in HUVEC supernatant SOD and MDA concentrations in the lovastatin and zhibituo groups exhibited no statistically significant differences $(\mathrm{P}>0.05)$. The suppressive effects of low- and middle-dose XMJ on the decrease in supernatant SOD concentration and on the increase in supernatant MDA concentration were significantly weaker than that of high-dose XMJ $(\mathrm{P}<0.05)$, thus, the effects were dependent on XMJ dosage (Fig. 3).

Effect of XMJ on the level of supernatant cytokines in the HUVEC injury model induced by $\mathrm{H}_{2} \mathrm{O}_{2}$. In the middle-dose XMJ group, the levels of cytokines were as follows: ICAM-1, 36.33 $\pm 7.32 \mathrm{ng} / \mathrm{l}$; VCAM-1, 36.66 $\pm 1.58 \mu \mathrm{g} / \mathrm{l}$; IL-1, $14.75 \pm 2.04 \mathrm{ng} / \mathrm{l} ; \mathrm{IL}-6,6.05 \pm 0.84 \mathrm{ng} / \mathrm{l} ; \mathrm{MMP}-2,0.671 \pm 0.07 \mu \mathrm{g} / \mathrm{l}$; and TIMP-2, 2605.99 $\pm 222.17 \mathrm{pg} / \mathrm{l}$. In the model group, ICAM-1 was 71.18 $\pm 6.67 \mathrm{ng} / \mathrm{l}$, VCAM-1 was $44.81 \pm 2.09 \mu \mathrm{g} / 1$, IL-1 was $18.34 \pm 2.14 \mathrm{ng} / 1$, IL-6 was $7.24 \pm 0.92 \mathrm{ng} / 1$, MMP-2 was $0.608 \pm 0.07 \mu \mathrm{g} / 1$ and TIMP-2 was $1739.31 \pm 254.39 \mathrm{pg} / 1$. No significant difference $(\mathrm{P}>0.05)$ was identified between the model and middle-dose XMJ groups. The levels of ICAM-1, VCAM-1, IL-1 and IL-6 decreased, while the levels of MMP-2 and TIMP-2 increased. Lovastatin and zhibituo demonstrated marked suppressive effects on the $\mathrm{H}_{2} \mathrm{O}_{2}$-induced increase in ICAM-1, VCAM-1, IL-1 and IL-6 levels and on the decrease in MMP-2 and TIMP-2 levels, which were all statistically significant $(\mathrm{P}<0.05)$ when compared with the model group. Compared with the middle-dose XMJ group, the levels of supernatant cytokines in the lovastatin with zhibituo groups exhibited no statistically significant differences $(\mathrm{P}>0.05)$. The suppressive effects of low-dose XMJ on the increase in ICAM-1, VCAM-1, IL-1 and IL-6 levels and on the decrease in MMP-2 and TIMP-2 levels in the HUVEC injury model 


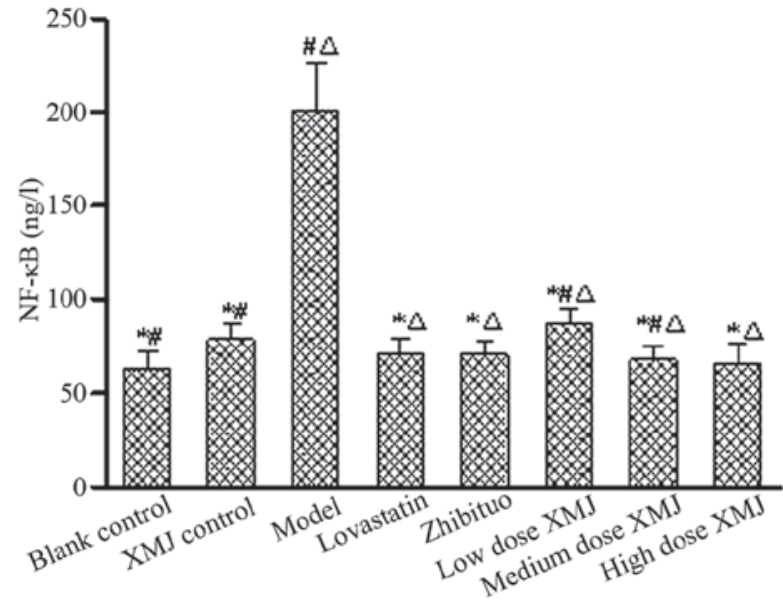

Figure 4. Effect of XMJ on the levels of NF-кB in the supernatant of HUVECs induced by $\mathrm{H}_{2} \mathrm{O}_{2} .{ }^{*} \mathrm{P}<0.05$, vs. model group; ${ }^{*} \mathrm{P}<0.05$, vs. high-dose XMJ group; ${ }^{\wedge} \mathrm{P}<0.05$, vs. blank control group. XMJ, Xin Mai Jia; HUVECs, human umbilical vein endothelial cells; NF, nuclear factor; $\mathrm{H}_{2} \mathrm{O}_{2}$, hydrogen peroxide.

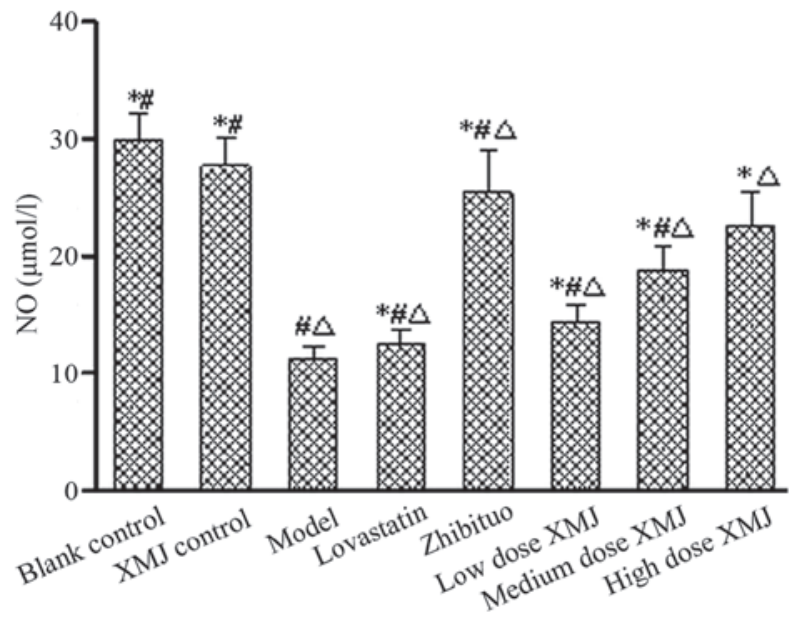

Figure 5. Effect of XMJ on the level of NO in the supernatant of HUVECs induced by $\mathrm{H}_{2} \mathrm{O}_{2}$. "P<0.05, vs. model group; ${ }^{*} \mathrm{P}<0.05$, vs. high-dose XMJ group; ${ }^{\triangle} \mathrm{P}<0.05$, vs. blank control group. XMJ, Xin Mai Jia; HUVECs, human umbilical vein endothelial cells; $\mathrm{NO}$, nitric oxide; $\mathrm{H}_{2} \mathrm{O}_{2}$, hydrogen peroxide.

induced by $\mathrm{H}_{2} \mathrm{O}_{2}$ were significantly weaker when compared with the middle-dose XMJ group $(\mathrm{P}<0.05)$. However, the suppressive effects of high-dose XMJ were weaker than those of middle-dose $\mathrm{XMJ}$; the reason is yet to be determined (Table II).

Effect of XMJ on the level of NF- $\mathrm{KB}$ in the supernatant of HUVECs induced by $\mathrm{H}_{2} \mathrm{O}_{2}$. In the high-dose XMJ group, the concentration of NF- $\mathrm{\kappa B}$ was $65.84 \pm 10.32 \mathrm{ng} / \mathrm{l}$, whereas the level in the model group was $200.46 \pm 25.68 \mathrm{ng} / \mathrm{l}$. Compared with the model group, the significant decrease in NF- $\kappa \mathrm{B}$ concentration in the high-dose XMJ group was statistically significant $(\mathrm{P}<0.05)$. Lovastatin and zhibituo exhibited marked suppressive effects on the increase in supernatant $\mathrm{NF}-\kappa \mathrm{B}$ concentration in the HUVEC injury model induced by $\mathrm{H}_{2} \mathrm{O}_{2}$, which were statistically significant $(\mathrm{P}<0.05)$ when

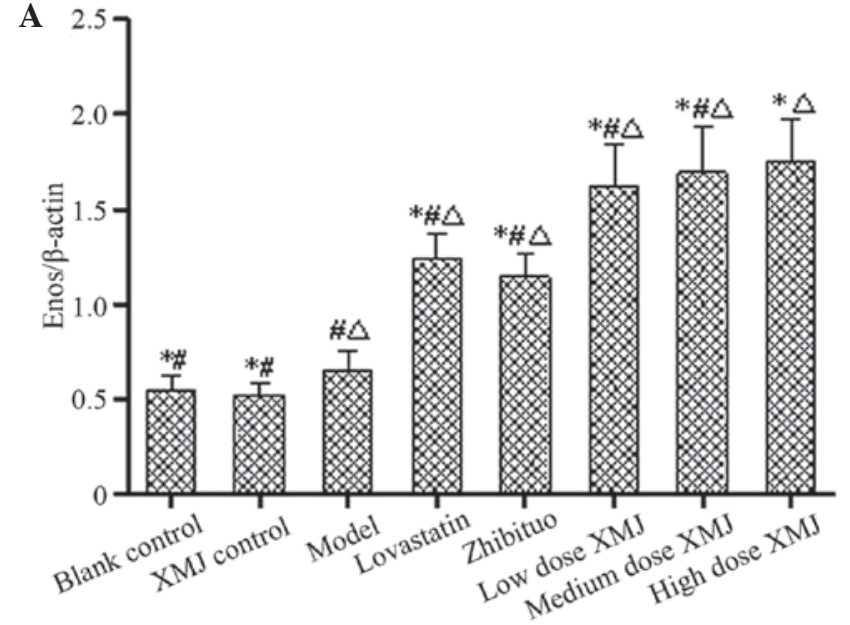

B

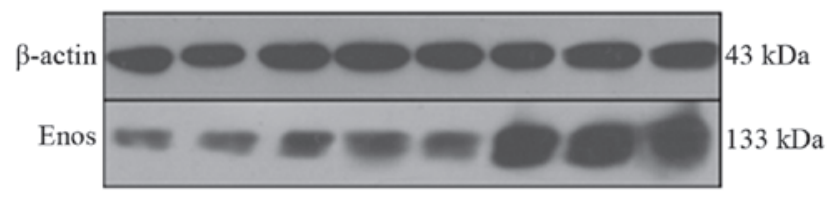

Figure 6. (A) Densitometric analysis of (B) western blot analysis showing the protein expression levels of eNOS in HUVECs. ${ }^{*}<<0.05$, vs. model group; ${ }^{\#} \mathrm{P}<0.05$, vs. high-dose $\mathrm{XMJ}$ group; ${ }^{\triangle} \mathrm{P}<0.05$, vs. blank control group. XMJ, Xin Mai Jia; HUVECs, human umbilical vein endothelial cells; eNOS, endothelial nitric oxide synthase.

compared with the model group. However, when compared with the high-dose XMJ group, the differences in NF-kB concentration in the lovastatin and zhibituo groups were not statistically significant $(\mathrm{P}>0.05)$. The suppressive effects of the low- and middle-dose XMJ groups on the increase in NF- $\mathrm{KB}$ concentration in the HUVECs induced by $\mathrm{H}_{2} \mathrm{O}_{2}$ were significantly weaker when compared with the high-dose XMJ group $(\mathrm{P}<0.05)$, thus, the effects were dependent on the dose of XMJ (Fig. 4).

Effect of XMJ on the level of $N O$ in the supernatant of HUVECs induced by $\mathrm{H}_{2} \mathrm{O}_{2}$. In the high-dose XMJ group, the concentration of $\mathrm{NO}$ was $22.58 \pm 2.58 \mu \mathrm{mol} / 1$, while in the model group, the concentration was $11.21 \pm 1.11 \mu \mathrm{mol} / 1$. The increase in NO concentration in the high-dose XMJ group exhibited a statistically significant difference $(\mathrm{P}<0.05)$ when compared with the model group. Lovastatin and zhibituo exhibited marked suppressive effects on the decrease in NO concentration in HUVECs induced by $\mathrm{H}_{2} \mathrm{O}_{2}$, which revealed statistically significant differences $(\mathrm{P}<0.05)$ when compared with the model group. However, the effect of the high-dose $\mathrm{XMJ}$ was more significant than that of lovastatin and zhibituo. The suppressive effects of low- and middle-dose XMJ on the $\mathrm{H}_{2} \mathrm{O}_{2}$-induced decrease in NO levels in the HUVECs were significantly weaker than that of high-dose XMJ $(\mathrm{P}<0.05)$, indicating that the effects were dependent on the dose of XMJ (Fig. 5).

Detection of eNOS concentration using western blot analysis. The concentration of eNOS/ $\beta$-actin was $1.75 \pm 0.22$ in the high-dose XMJ group and $0.65 \pm 0.11$ in the model group. The 
A

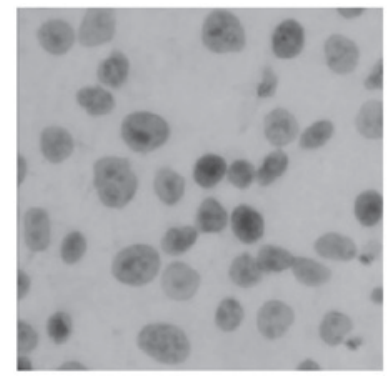

E

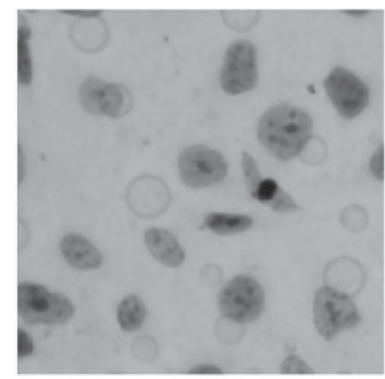

B

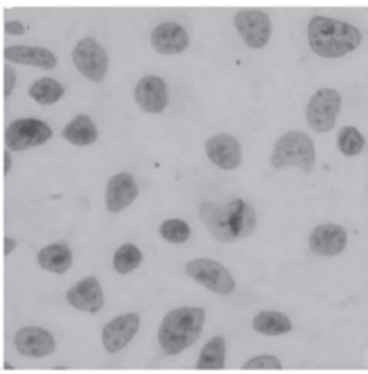

F

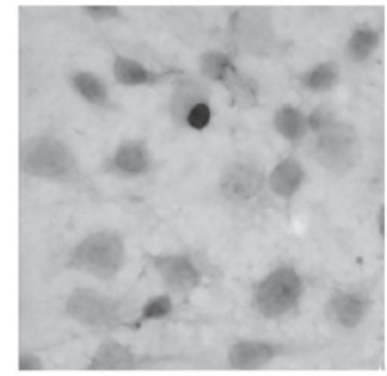

C

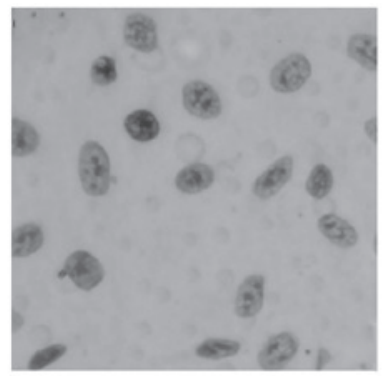

G

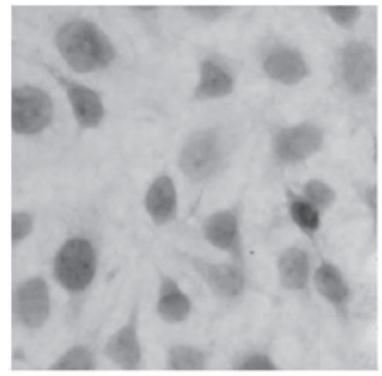

D

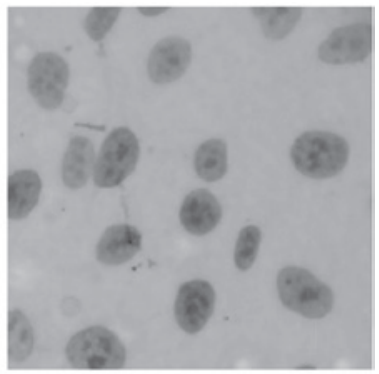

H

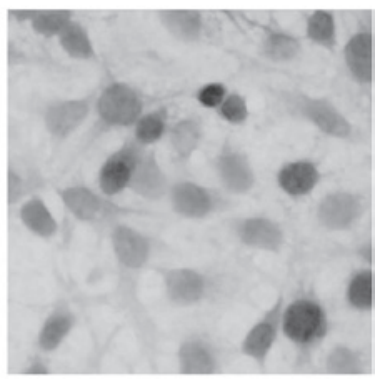

Figure 7. Immunohistochemical analysis (immunohistochemistry, Mayer's hematoxylin counterstain) was used to detect the eNOS protein content in HUVECs (magnification, $\mathrm{x} 400$ ) in the (A) blank control, (B) XMJ control, (C) model, (D) lovastatin, (E) zhibituo, (F) low-dose XMJ, (G) medium-dose XMJ and (H) high-dose XMJ groups. XMJ, Xin Mai Jia; HUVECs, human umbilical vein endothelial cells; eNOS, endothelial nitric oxide synthase.

significant increase in eNOS/ $\beta$-actin levels observed in the high-dose XMJ group was statistically significant $(\mathrm{P}<0.05)$ when compared with the model group. Lovastatin and zhibituo exhibited marked suppressive effects on the decrease in eNOS concentration in the HUVECs induced by $\mathrm{H}_{2} \mathrm{O}_{2}$, which was statistically significant $(\mathrm{P}<0.05)$ when compared with the model group. The suppressive effect of high-dose XMJ on the decrease in eNOS content was more significant than those of lovastatin and zhibituo $(\mathrm{P}<0.05)$. In addition, the levels of eNOS $/ \beta$-actin in the low- and middle-dose XMJ groups were significantly weaker than that of the high-dose XMJ group $(\mathrm{P}<0.05)$, indicating that the effects were dependent on $\mathrm{XMJ}$ dosage (Fig. 6).

Determination of eNOS protein concentration using immunohistochemistry. In the high-dose XMJ group, the degree of eNOS staining saturation was $7.23 \pm 0.29 \%$, the chromaticity was $42.55 \pm 3.27 \%$, the grayscale value was $254.33 \pm 11.39 \%$, the red value was $153.98 \pm 12.97 \%$, the green value was $178.98 \pm 15.23 \%$ and the blue value was $165.38 \pm 11.27 \%$. In the model group, the degree of eNOS staining saturation was $16.55 \pm 0.67 \%$, the chromaticity was $33.78 \pm 2.17$, the grayscale value was $189.46 \pm 12.54$, the red value was $136.59 \pm 11.22$, the green value was $154.78 \pm 13.24$ and the blue value was $144.29 \pm 12.67$. A significant difference $(\mathrm{P}<0.05)$ was observed in the eNOS coloration index between the high-dose XMJ and model groups. Lovastatin and zhibituo exhibited significant effects on the eNOS coloration index of the HUVEC model induced by $\mathrm{H}_{2} \mathrm{O}_{2}$, which were statistically significant $(\mathrm{P}<0.05)$ when compared with the model group. The eNOS staining indicators in the high-dose $\mathrm{XMJ}$ group were greater than those in the lovastatin and zhibituo groups $(\mathrm{P}<0.05)$. The effect of low- and middle-dose XMJ on the eNOS coloration index in the HUVECs induced by $\mathrm{H}_{2} \mathrm{O}_{2}$ were markedly weaker than that of the high-dose XMJ group, indicating XMJ dose dependence (Fig. 7).
Determination of eNOS content using immunofluorescence. Confocal fluorescence tomography was performed on immunofluorescence cells with a laser scanning confocal microscope. The 32 facets of each cell were scanned and the fluorescence intensity within the cells was detected using fluorescence quantitative analysis software. The eNOS protein was predominantly expressed in the cytoplasm of the HUVECs. The positive signals presented yellowish-green spotlight, with diffused distribution. The fluorescence intensity values of the eNOS protein were $178.33 \pm 11.26$ in the high-dose XMJ group and 65.27 \pm 4.66 in the model group, which exhibited a statistically significant difference $(\mathrm{P}<0.05)$. Lovastatin and zhibituo significantly increased $(\mathrm{P}<0.05)$ the fluorescence intensity of the eNOS protein in the HUVECs induced by $\mathrm{H}_{2} \mathrm{O}_{2}$. However, the fluorescence intensity of the eNOS protein in the high-dose XMJ group was greater than those in the lovastatin and zhibituo groups $(\mathrm{P}<0.05)$ The fluorescence intensities of the eNOS protein in the HUVECs treated with low- and middle-dose XMJ were significantly weaker than that of high-dose XMJ $(\mathrm{P}<0.05)$, indicating XMJ dose dependence (Fig. 8).

Detection of eNOS gene expression levels using fluorescence $q P C R$. Fluorescence intensity values of eNOS gene expression were $3.96 \pm 0.36$ in the high-dose $\mathrm{XMJ}$ group and $0.55 \pm 0.77$ in the model group; the results exhibited a statistically significant difference $(\mathrm{P}<0.05)$. Lovastatin and zhibituo significantly increased $(\mathrm{P}<0.05)$ the fluorescence intensity of eNOS gene expression in the HUVECs induced by $\mathrm{H}_{2} \mathrm{O}_{2}$ when compared with the model group. The fluorescence intensity of eNOS gene expression in the high-dose XMJ group was greater than those of the lovastatin and zhibituo groups $(\mathrm{P}<0.05)$. The fluorescence intensities of eNOS gene expression in the low- and middle-dose XMJ groups were significantly weaker than that of the high-dose XMJ group $(\mathrm{P}<0.05)$, thus, the effects were dependent on XMJ dosage (Fig. 9). 
A

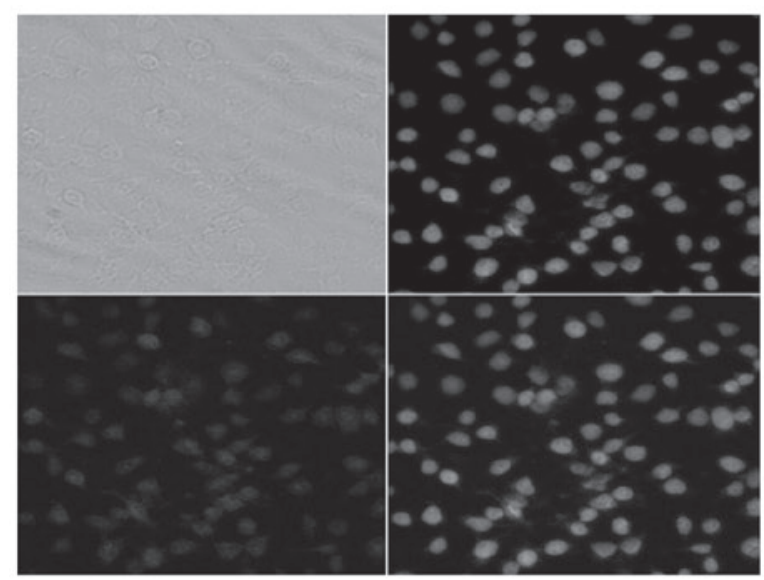

C

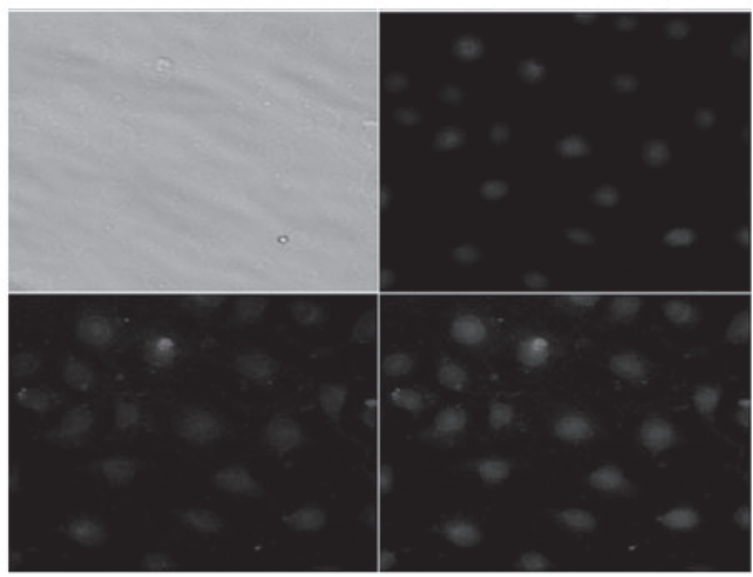

$\mathbf{E}$

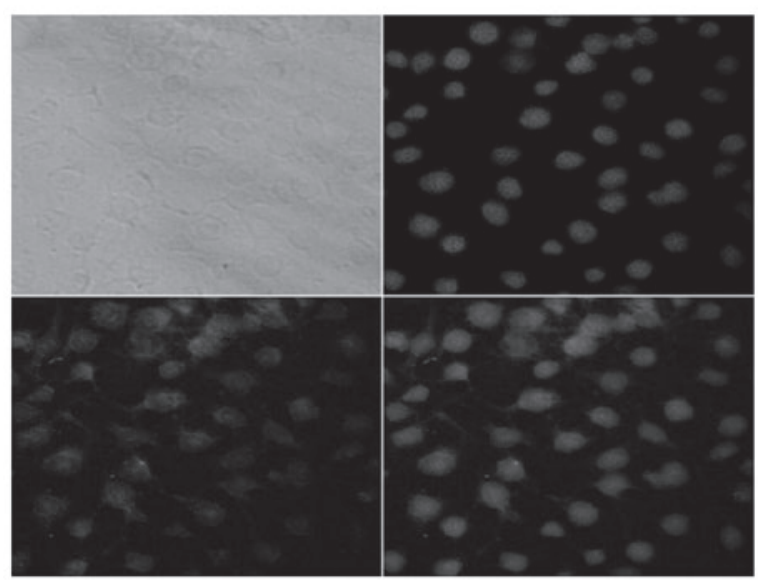

G

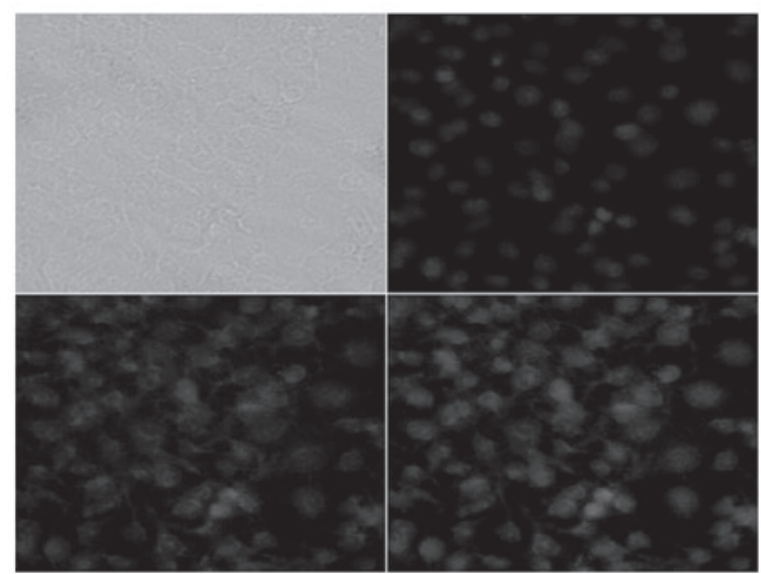

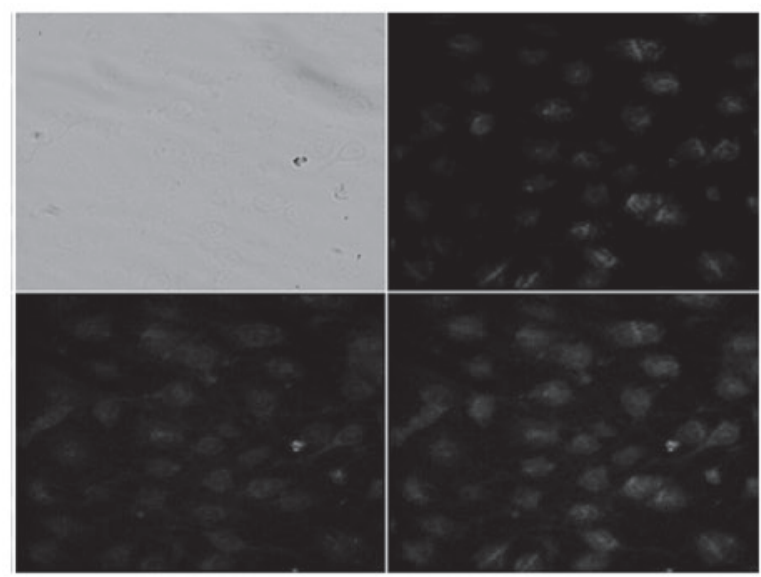

D

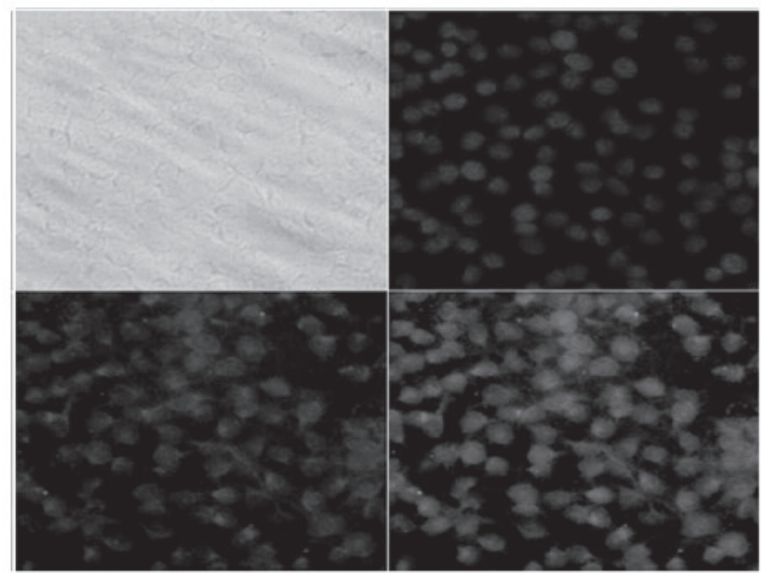

$\mathbf{F}$

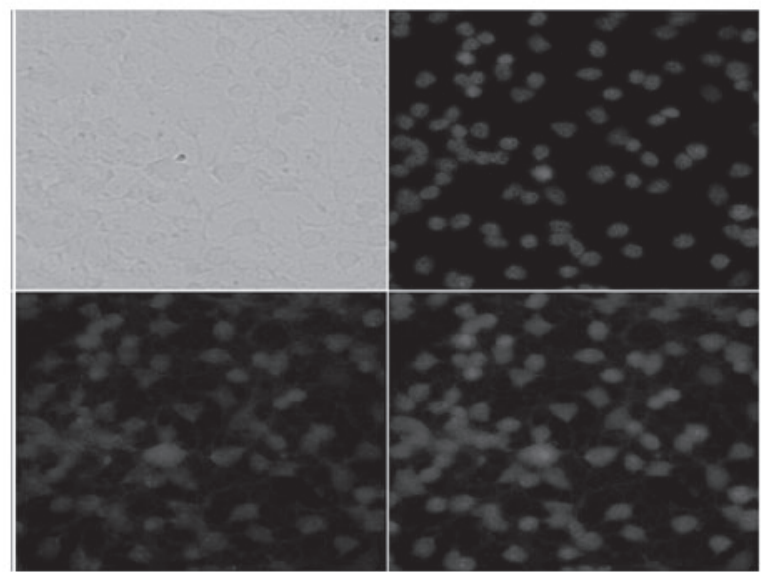

$\mathbf{H}$

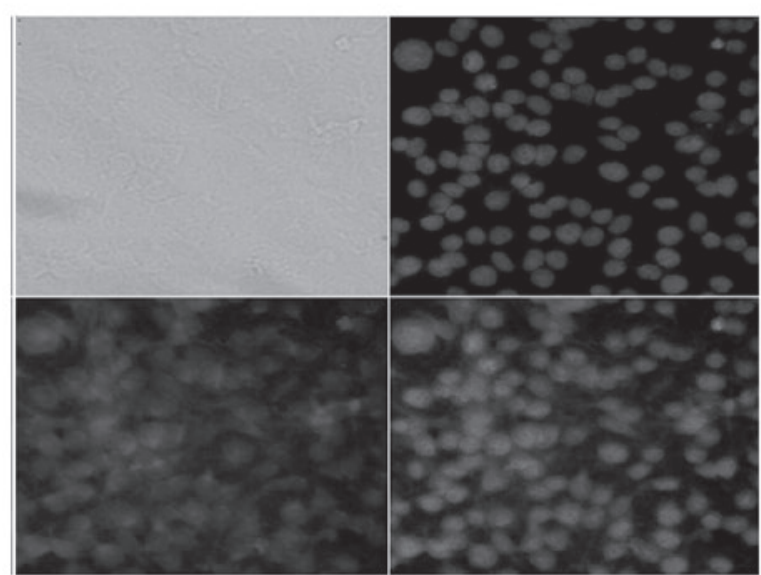

Figure 8. Immunofluorescence analysis was used to detect the levels of eNOS in HUVECs (magnification, $\mathrm{x} 400$ ) in the (A) blank control, (B) XMJ control, (C) model, (D) lovastatin, (E) zhibituo, (F) low-dose XMJ, (G) medium-dose XMJ and (H) high-dose XMJ groups. XMJ, Xin Mai Jia; HUVECs, human umbilical vein endothelial cells; eNOS, endothelial nitric oxide synthase. 


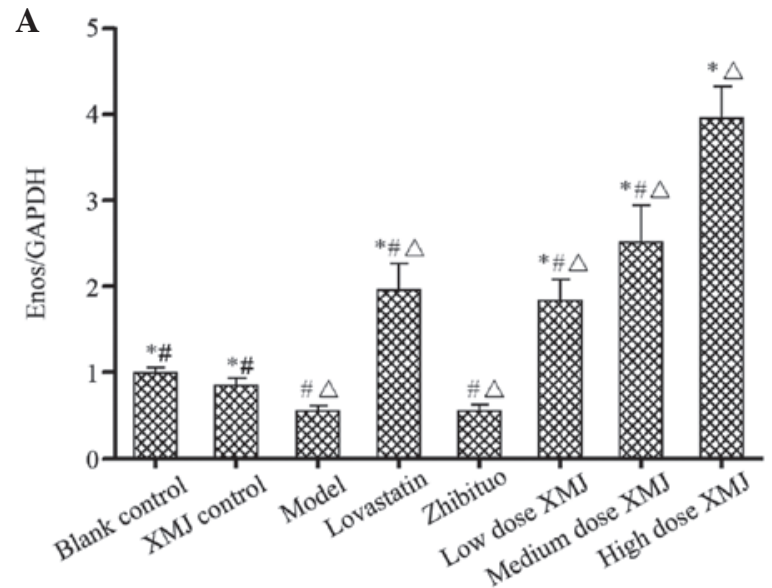

B

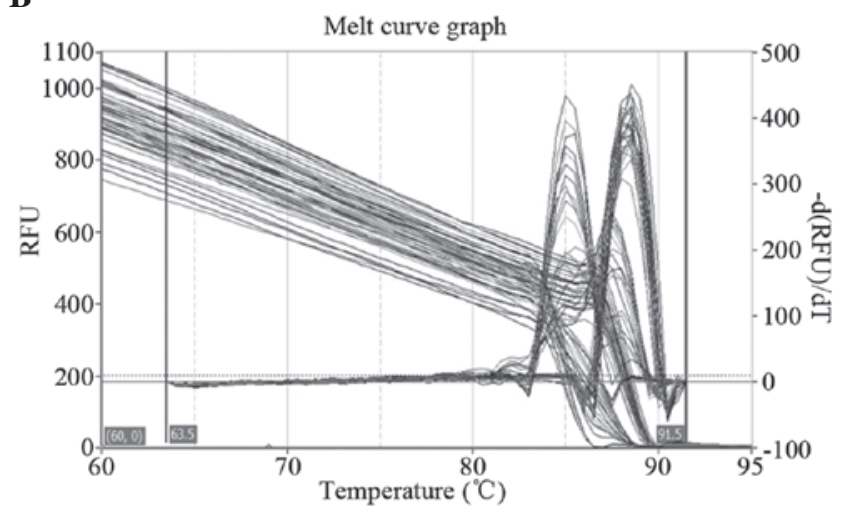

C

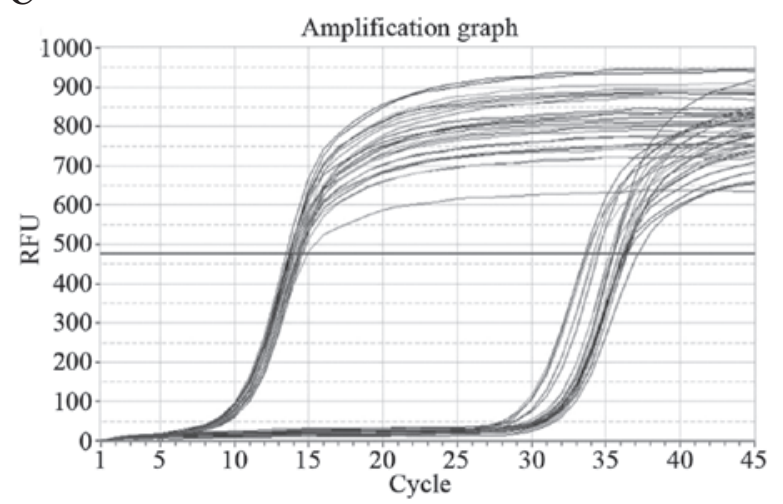

Figure 9. Fluorescence qPCR was used to detect the gene expression levels of eNOS in HUVECs. (A) Gene expression levels; (B) Melt curve; (C) amplification curve. $\mathrm{P}<0.05$, vs. model group; ${ }^{*} \mathrm{P}<0.05$, vs. high-dose $\mathrm{XMJ}$ group; ${ }^{\wedge} \mathrm{P}<0.05$, vs. blank control group. XMJ, Xin Mai Jia; HUVECs, human umbilical vein endothelial cells; eNOS, endothelial nitric oxide synthase; qPCR, quantitative polymerase chain reaction.

\section{Discussion}

$\mathrm{NO}$ in the body results from the activation of the $\mathrm{N}$-methyl-D-aspartate receptor and the catalysis of NOS. NOS widely exists in the nervous system, internally and externally. NOS isoenzymes are classified into three subtypes: Neuronal NOS (nNOS), eNOS and immune-NOS. nNOS and eNOS have $\mathrm{Ca} 2+-$ dependent structural expressions, which exist in normal physiological state (15). NF- $\kappa \mathrm{B}$, an important transcription factor, regulates the expression of various genes involved in inflammation and immune processes, and is closely associated with several important pathophysiologies, including cell proliferation, transformation and apoptosis (16). In the development of $\mathrm{AS}$, the expression of $\mathrm{NF}-\kappa \mathrm{B}$, induced by a variety of pathogenic factors, increases, stimulating the increased secretion of IL-1, IL-6, ICAM-1, VCAM-1 and other inflammatory cytokines. In addition, $\mathrm{NF}-\kappa \mathrm{B}$ inhibits eNOS expression, reduces NO release and decreases normal vasomotion function. As a secondary intracellular messenger in HUVECs, NO increases the concentration of cGMP via the cGMP pathway. This phenomenon can influence ion channels or phosphodiesterase activity, activate cGMP-dependent protein kinase, activate cycloxygenase, protein kinase $\mathrm{C}$ and iron regulatory proteins, stimulate the expression of the early gene response or inhibit $\mathrm{NF}-\kappa \mathrm{B}$ and other non-cGMP pathways.

The majority of studies show that XMJ exhibits a marked protective effect on HUVEC injury induced by $\mathrm{H}_{2} \mathrm{O}_{2}$. This protective effect is dependent on the dose of XMJ $(17,18)$. However, by studying the effect that XMJ has on the level of supernatant cytokines in HUVECs induced by $\mathrm{H}_{2} \mathrm{O}_{2}$, the protective effects of low- and middle-dose XMJ were shown to be dependent on XMJ dosage to a certain extent, whereas the suppressive effects of high-dose XMJ were weaker than those of middle-dose XMJ. In the high-dose XMJ group, cytokine levels were as follows: ICAM-1, 39.29 $44.57 \mathrm{ng} / \mathrm{l}$; VCAM-1,

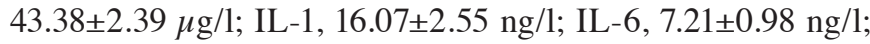
MMP-2, 0.643 $\pm 0.07 \mu \mathrm{g} / \mathrm{l}$; and TIMP-2, $1579.37 \pm 123.47 \mathrm{pg} / 1$. This variation may possibly be attributed to the disproportion between the secretion and expression levels of the cytokines within the HUVEC supernatant, however, the specific reasons require further investigation.

MMP-2 belongs to the MMP family, which requires $\mathrm{Ca}^{2+}$, $\mathrm{Zn}^{2+}$ and other metal ions as cofactors for protein hydrolysis. MMP-2 consists of five functional domains. Firstly, a hydrophobic signaling peptide sequence. Secondly, the pre-peptide region, which functions in maintaining the stability of the proenzyme, as the MMP-2 zymogen is activated when the region is cut off by an exogenous enzyme. Thirdly, the catalytic activity area, which is a $\mathrm{Zn}^{2+}$ binding site that plays a crucial role in enzyme catalysis. Fourthly, the hinge region that contains abundant proline residues. Finally, there is the carboxyl terminal region, which is associated with the specificity of the enzyme substrate. The MMP-2 gene, which consists of 13 exons and 12 introns, is located on the $16 \mathrm{q} 21$ human chromosome. The total length of the structural gene is $27 \mathrm{~kb}$, which differs from other MMPs due to the MMP-2 gene 5 ' flanking sequence that contains two GC boxes instead of two TATA sequences, which promotes the subregion (19). MMP-2 can decompose the stromal component among the cells and type IV collagen, which is the main component of the basement membrane (20-22). Previous studies have reported that the expression of MMP-2 increases during early AS pathogenesis. However, following drug intervention, MMP-2 expression decreases, which confirmed the increase in MMP-2 to be an iconic indicator of AS (23-29). However, experimental data have produced contradictory results. In the present study, the level of MMP-2 in the model group was $0.608 \pm 0.07 \mu \mathrm{g} / 1$, which was a marked decrease when compared with the blank control group, whereas the level of MMP-2 in the drug groups increased significantly. This difference may be associated with the secretion and disproportionate expression levels of 
cytokines in the supernatant fluid of the HUVECs, however, if XMJ is able to increase the levels of MMP-2, then the degradation of matrix proteins increases. This difference may be relevant with the ablation of the AS plaque. In the present study, the level of TIMP-2 in the drug groups increased, which may be attributable to a feedback mechanism from the body.

In order to determine whether XMJ itself exhibits harmful effects on the HUVEC model, which may have significantly affected the experimental data, a control group of XMJ drug media was used in the experiment. The results demonstrated that XMJ itself presents no harm to the HUVECs and does not affect the experimental results. Lovastatin and zhibituo are chemical drugs and TCM commonly used for the treatment of AS in clinical practice. Lovastatin and zhibituo were selected as the control drugs to ascertain the degree of the protective effect of XMJ on HUVEC injury induced by $\mathrm{H}_{2} \mathrm{O}_{2}$. The majority of the results indicated that the protective effects of XMJ on HUVEC injury induced by $\mathrm{H}_{2} \mathrm{O}_{2}$ were greater than those of lovastatin and zhibituo. However, the differences in the levels of SOD, MDA and NF- $\kappa \mathrm{B}$ in the HUVEC supernatant among the high-dose XMJ, lovastatin and zhibituo groups presented no statistical significance $(\mathrm{P}>0.05)$. In addition, the difference in the levels of cytokines in the HUVEC supernatant among the middle-dose XMJ, lovastatin and zhibituo groups was not statistically significant $(\mathrm{P}>0.05)$. We hypothesize that these observations may have resulted from the dilution of cytokines in the HUVEC supernatant fluid or may be associated with the level of secretion. In conclusion, Xin Mai Jia prevents atherosclerosis and is superior to routine anti-atherosclerosis drugs such as lovastatin and Zhibituo.

\section{Acknowledgements}

The study was supported by a grant from the Major Research Projects of the Department of Science and Technology of Henan Province, China (no. 121100910300).

\section{References}

1. Aliev G, Li Y, Palacios HH and Obrenovich ME: Oxidative stress induced mitochondrial DNA deletion as a hallmark for the drug development in the context of the cerebrovascular diseases. Recent Pat Cardiovasc Drug Discov 6: 222-241, 2011.

2. Kotsovolis G and Kallaras K: The role of endothelium and endogenous vasoactive substances in sepsis. Hippokratia 14: 88-93, 2010

3. Czyzewska-Buczyńska A and Witkiewicz W: Role of mast cells in the pathogenesis of atherosclerosis. Przegl Lek 68: 171-174, 2011 (In Polish).

4. Petrofsky JS: The effect of type-2-diabetes-related vascular endothelial dysfunction on skin physiology and activities of daily living. J Diabetes Sci Technol 5: 657-667, 2011.

5. Liu R, Wu S, Cao G, Wang W, Liu K and Wu S: Transfection of human hepatocyte growth factor gene inhibits advancing pulmonary arterial hypertension induced by shunt flow in a rabbit model. Transplant Proc 45: 705-712, 2013.

6. Perez-Herrera A, Rangel-Zuñiga OA, Delgado-Lista J, et al: The antioxidants in oils heated at frying temperature, whether natural or added, could protect against postprandial oxidative stress in obese people. Food Chem 138: 2250-2259, 2013.

7. Razavi SM, Gholamin S, Eskandari A, et al: Red grape seed extract improves lipid profiles and decreases oxidized low-density lipoprotein in patients with mild hyperlipidemia. J Med Food 16 255-258, 2013

8. Rocha BS, Gago B, Pereira C, et al: Dietary nitrite in nitric oxide biology: a redox interplay with implications for pathophysiology and therapeutics. Curr Drug Targets 12: 1351-1363, 2011.
9. Wan J, Yin Y, Sun R, et al: Protective effect of the ultra-filtration extract from Xin Mai Jia on human aortic smooth muscle cell injury induced by hydrogen peroxide. Exp Ther Med 7: 11-16, 2014.

10. Wilcox JN, Subramanian RR, Sundell CL, et al: Expression of multiple isoforms of nitric oxide synthase in normal and atherosclerotic vessels. Arterioscler Thromb Vasc Biol 17: 2479-2488, 1997.

11. Wan GR, Wan J, Dong XH, et al: The preparative method of a kind of supplement food with the effect of adjusting blood-fat and antagonism to artherosclerosis. China patent (No. 201010536001) (In Chinese).

12. Postlethwaite AE, Snyderman R and Kang AH: The chemotatic attraction of human fibroblasts to a lymphocyte-derived factor. J Exp Med 144: 1188-1203, 1976.

13. Ding ZQ, Li SH and Wu ZL: The effect of platelet activating factor on endothelial monolayer permeability by extracorporeal perfusion. Di Er Jun Yi Da Xue Xue Bao 14: 101-106, 1993 (In Chinese).

14. Ni L, Li T, Liu B, et al: The protective effect of Bcl-xl overexpression against oxidative stress-induced vascular endothelial cell injury and the role of the Akt/eNOS pathway. Int J Mol Sci 14: 22149-22162, 2013.

15. Das T, Bhattacharya S, Biswas A, Gupta SD, Gomes A and Gomes A: Inhibition of leukemic U937 cell growth by induction of apoptosis, cell cycle arrest and suppression of VEGF, MMP-2 and MMP-9 activities by cytotoxin protein NN-32 purified from Indian spectacled cobra (Naja naja) venom. Toxicon 65: 1-4, 2013.

16. Lee JH, Shim JW, Choi YJ, Heo K and Yang K: The combination of sorafenib and radiation preferentially inhibits breast cancer stem cells by suppressing HIF-1 $\alpha$ expression. Oncol Rep 29: 917-924, 2013.

17. Shahlaee A, Farahanchi A, Javadi S, Delfan B and Dehpour AR: Sucrose-induced analgesia in mice: role of nitric oxide and opioid receptor-mediated system. Indian J Pharmacol 45: 593-596, 2013.

18. Han C, Zhao Q and Lu B: The role of nitric oxide signaling in food intake; insights from the inner mitochondrial membrane peptidase 2 mutant mice. Redox Biol 1: 498-407, 2013.

19. Sasaki T, Nakamura K, Sasada K, et al: Matrix metalloproteinase-2 deficiency impairs aortic atherosclerotic calcification in ApoE-deficient mice. Atherosclerosis 227: 43-50, 2013.

20. Jeong YJ, Cho HJ, Whang K, et al: Melittin has an inhibitory effect on TNF- $\alpha$-induced migration of human aortic smooth muscle cells by blocking the MMP-9 expression. Food Chem Toxicol 50: 3996-4002, 2012.

21. Xu YZ, Zhao KJ, Yang ZG, et al: Decreased plasma decorin levels following acute ischemic stroke: correlation with MMP-2 and differential expression in TOAST subtypes. Mol Med Rep 6: 1319-1324, 2012

22. Kang SW, Kim MS, Kim HS, et al: Celastrol attenuates adipokine resistin-associated matrix interaction and migration of vascular smooth muscle cells. J Cell Biochem 114: 398-408, 2013.

23. Miksztowicz V, Siseles N, Fernandez Machulsky N, Schreier L and Berg G: Increase in MMP-2 activity in overweight and obese women is associated with menopausal status. Climacteric 15: 602-606, 2012.

24. Soumyarani VS and Jayakumari N: Oxidatively modified high density lipoprotein promotes inflammatory response in human monocytes-macrophages by enhanced production of ROS, TNF- $\alpha$, MMP-9, and MMP-2. Mol Cell Biochem 366: 277-285, 2012.

25. Karki R, Jeon ER and Kim DW: Magnoliae Cortex inhibits intimal thickening of carotid artery through modulation of proliferation and migration of vascular smooth muscle cells. Food Chem Toxicol 50: 634-640, 2012.

26. Ibanez B, Giannarelli C, Cimmino G, et al: Recombinant HDL (Milano) exerts greater anti-inflammatory and plaque stabilizing properties than HDL (wild-type). Atherosclerosis 220: 72-77, 2012.

27. Butoi ED, Gan AM, Manduteanu I, et al: Cross talk between smooth muscle cells and monocytes/activated monocytes via CX3CL1/CX3CR1 axis augments expression of pro-atherogenic molecules. Biochim Biophys Acta 1813: 2026-2035, 2011.

28. Cheng XW, Song H, Sasaki T, et al: Angiotensin type 1 receptor blocker reduces intimal neovascularization and plaque growth in apolipoprotein E-deficient mice. Hypertension 57: 981-989, 2011.

29. Yi L, Chen CY, Jin X, et al: Differential suppression of intracellular reactive oxygen species-mediated signaling pathway in vascular endothelial cells by several subclasses of flavonoids. Biochimie 94: 2035-2044, 2012. 